en continua transformación, haciéndose; en el que no hay un centro que aporte una definición única y verdadera y que se construye en las interacciones con otras.

Nos vamos acercando a la propuesta teórico-analítica para el estudio de los movimientos feministas en proceso. Para Martínez el problema sobre la identidad colectiva al que nos enfrentamos es que este concepto es empleado siempre como definición y, como tal, supone la alineación con la lectura moderna de la identidad que da por hecho que una definición acabará imponiéndose sobre las demás como la verdadera. El nuevo modelo propone una definición de la identidad colectiva ampliada al incorporar las emociones y las relaciones, y en cuyo proceso de formación el eje principal será lo procesual a través de los conceptos de reiteración y activación. Ante la imposibilidad de plantear un modelo teórico y empírico total para el estudio de la construcción de la identidad colectiva de cualquier movimiento social, nos plantea una ideareto, una «propuesta abierta, en construcción si se quiere, que busca aportar algunas pistas sobre cómo encarar el estudio de las identidades colectivas hoy». Una propuesta teórico-analítica que solo ha sido posible desarrollar en el estudio de las identidades feministas en proceso.

En conclusión, el libro nos hace reflexionar lúcidamente sobre la tendencia de las teorías de los movimientos sociales a la cosificación de dichos movimientos que parecen entes con vida propia, con unos objetivos definidos y unos fines claros a alcanzar. La utilización del movimiento feminista es muy jugosa al ser un movimiento particularmente fragmentado y en continuo auto cuestionamiento.

por Almudena de LINOS ESCARIO Universidad Nacional de Educación a Distancia (UNED) almudenadelinos@gmail.com

\title{
The Historical Roots of Political Violence
}

\author{
Ignacio Sánchez-Cuenca
}

(Cambridge, Cambridge University Press, 2019)

Este libro de Sánchez-Cuenca, que culmina y trasciende su larga trayectoria de estudios sobre violencia política y terrorismo, entre los que destacan sus análisis sobre ETA, parte de una pregunta que acota el tema y su marco comparativo: ¿por qué en la década de los años sesenta y setenta dentro de las sociedades avanzadas muchos jóvenes de clases medias y profesionales se alzan en armas contra el sistema? Fuera quedan, por tanto, la violencia y el terrorismo de movimientos independentistas dentro de esos países avanzados, como ETA o el IRA, así como los de grupos anticolonialistas, islamistas o xenófobos, no relacionados directamente con las cuestiones distributivas clásicas que separaban 
a izquierda y derecha. La violencia revolucionaria de izquierdas en los países avanzados se enfoca no solo como un problema de seguridad sino como una manifestación más del conflicto político, social y económico de los macroprocesos de cambio, ocurridos antes de la aparición de la violencia y que son caldo de cultivo necesario, pero no suficiente, para un estallido revolucionario para el que se precisan factores que actúen como detonantes.

Lo nuevo de este estudio no es tanto la pregunta cuanto la investigación pluridimensional y de larga duración, en la que múltiples disciplinas (historia social, política y económica, ciencia política, antropología, psicología social, relaciones internacionales, economía...) se entrecruzan para servir de base a un análisis del terrorismo revolucionario en los 23 países seleccionados (todos miembros de la OCDE antes de 1994, salvo Turquía). El estudio combina el examen histórico pormenorizado de cada uno de los casos, la comparación cualitativa y el análisis estadístico que, como sostiene el autor, es fundamental para disciplinar argumentos e hipótesis y para identificar las excepciones. La muestra permite un diseño con un $N$ amplio en que la variable dependiente, el terrorismo, se mide por el número de atentados por país y año, mientras las variables independientes son los diversos componentes de los macroprocesos, los «sospechosos habituales»: PIB per cápita, crecimiento económico, desigualdad, régimen político, represión del Estado, fragmentación religiosa y política, población, instituciones, etc. (página 13).

La principal hipótesis del libro es que el terrorismo revolucionario de los años sesenta y setenta, en el que las movilizaciones de 1968 actuaron como detonante, en gran medida reproduce los clivajes del período de entreguerras y se concentra en el clúster de aquellos países que en esos años no llegaron a un cierto compromiso de clase y en los que quebró o no se desarrolló la democracia liberal. Lo relevante, y lo que plantea la cuestión del peso del desarrollo histórico anterior, es que esto ocurre en la posguerra, cuando hay una convergencia entre los sistemas políticos y económicos de los dos clústeres de entreguerras, el de los países liberales y el de los no liberales.

El libro se estructura en dos partes diferenciadas. En la primera se desarrolla el argumento de la obra, el resurgimiento del radicalismo revolucionario en la década dorada de los 60-70, la aparición de nuevos movimientos sociales, de una nueva izquierda y del marginado como un nuevo sujeto revolucionario, y se hace la pregunta sobre los factores que conducen, o no, a la violencia revolucionaria. Sigue la exposición de los caracteres del terrorismo revolucionario y las raíces ideológicas de la violencia concebida como un instrumento para fomentar la acción colectiva que, a diferencia de lo que ocurre con el terrorismo nacionalista (tanto en Irlanda como en el País Vasco), apenas se traduce a efectos prácticos en un gran aumento de seguidores, salvo parcialmente en Italia. Tras esta introducción se estudia el perfil del terrorismo revolucionario en el mundo desarrollado, la influencia ejercida por la revolución cubana y las luchas de liberación decolonial y nacional, como la de Argelia, así como las diferencias nacionales en los ciclos de violencia, el tipo de grupos y la «cualidad» de la misma, generalmente selectiva, tanto en el tipo de víctimas como en la violencia utilizada (cuadro 2.2). Esta primera parte termina con un examen del tipo de protestas que, en 1968, preceden a la aparición del terrorismo revolucionario, en las que se da un patrón común, aunque a ritmos diferentes. El terrorismo aparece como un último recurso cuando decae el ciclo de movilización, como se muestra en el análisis en detalle de los casos más importantes (Italia, España, Japón y Alemania, con Grecia y Portugal como dos casos menores).

La segunda parte, analítica, se centra en los efectos contemporáneos y las condiciones de fondo. Se inicia con un análisis empírico de las variables contemporáneas (corto plazo), 
con un interés en la variación transversal de la serie (TSCS) que se completa con un segundo análisis transversal que incluye las variables que, como la información histórica, varían poco a lo largo del tiempo. Uno de los problemas es que no siempre se cuenta con datos concretos sobre el tamaño de una izquierda radical que en su mayor parte es clandestina y extraparlamentaria, por lo que se recurre a otros indicadores como la fuerza del partido comunista, el nivel de actividad contestataria, incluidas las huelgas, la desigualdad de ingresos y el papel del Estado, incluyendo como variables de control, entre otras, el PIB per cápita, las tasas de crecimiento, datos demográficos diferenciados por edades y algunas otras variables explicativas como el sistema electoral, la participación, el número de partidos, la religiosidad, los medios de comunicación, etc. (página 107 y siguientes.). Los resultados indican que, en principio, el terrorismo revolucionario tuvo un suelo más fértil en países menos desarrollados en los años sesenta (salvo Alemania), aunque la explicación es insuficiente.

Sánchez-Cuenca amplía entonces la investigación a los determinantes a largo plazo y se centra en el periodo histórico de entreguerras, que examina en los capítulos 5 y 6 , en los que se estudia la conexión entre el desarrollo político y económico y el terrorismo. Para el análisis estadístico se seleccionan seis indicadores del tipo de desarrollo. Se trata de variables heterogéneas: intensidad del terrorismo anarquista entre 1878-1925, quiebra de la democracia de entreguerras, guerras civiles, desigual distribución de la tierra en ese período, tiempos y ritmos de la industrialización y el capitalismo liberal (ya que en los países más avanzados las clases obreras estuvieron más integradas en el sistema). El análisis estadístico muestra una fuerte relación entre el desarrollo de entreguerras y la intensidad del terrorismo revolucionario (páginas 171-177).

Los dos capítulos siguientes desarrollan los resultados y analizan los mecanismos históricos, los basados en la legitimidad del Estado y en el apoyo al extremismo, que se aborda desde una doble estrategia (histórica y sociológica) dado que se trata de dos tipos de desarrollo, el histórico de entreguerras (macro) y el del terrorismo revolucionario (micro). Apoyado en una amplia literatura multidisciplinar, Sánchez-Cuenca estudia la importancia de apoyo popular y de las creencias y actitudes de la izquierda. Dado que en este caso los datos son escasos y difíciles de utilizar comparativamente, la estrategia seguida por el autor es un ejercicio de "coherencia de las inducciones» (Whewell, 1988) según la cual una hipótesis puede explicar y conectar hechos aparentemente no relacionados. Una importante conclusión es que la legitimidad del Estado es un factor clave en los dos clústeres: los grupos terroristas que renunciaron al asesinato se concentran en el clúster de países en los que sobrevivió la democracia en el periodo de entreguerras, mientras que en aquellos con pasado no liberal los terroristas asumieron que podían emplear una violencia extrema y que aun así continuarían teniendo apoyos (página 214).

Un muy interesante último capítulo, en el que la aproximación interdisciplinar es aún más dominante, examina las relaciones entre el individualismo, la modernización y la violencia. Para evitar el riesgo de endogenismo (el individualismo como resultado y no como factor), el autor emplea proxis del pasado lejano, como la estructura familiar y las reglas gramaticales, que permiten medir con mayor precisión el individualismo y el colectivismo, tanto el excluyente del grupo propio, como el institucional que se abre a los grupos externos. El pormenorizado análisis estadístico (tablas 7.2 y siguientes) indica que el individualismo y los valores culturales no son necesariamente endógenos con relación a las variables. Los resultados son concluyentes: «el individualismo es relevante para dar cuenta tanto de las vías de desarrollo seguidas en el período de entreguerras como del terrorismo 
revolucionario de 1970-2000" (página 235) y que fue en las culturas dominadas por el colectivismo excluyente, del grupo propio, en las que se recurrió a la violencia letal.

Las nuevas formas de violencia, como las xenofóbicas o el terrorismo islamista, según el autor, no están relacionadas con las cuestiones distributivas clásicas que caracterizaban al terrorismo revolucionario como desafío armado al «sistema» capitalista y democrático, una última resistencia frente a su avance. Pero, concluye Sánchez-Cuenca, aunque el individualismo tuviera un gran peso, el terrorismo revolucionario «emergió como una combinación de acontecimientos a corto plazo y procesos de desarrollo a largo plazo en que el azar y la necesidad se vinculan» (página 242).

En suma, se trata de un libro que es un verdadero tour de force, altamente recomendable para los estudiosos del tema y para todos aquellos que se preguntan por una metodología adecuada para analizar el entrecruzamiento de los procesos de larga duración, las ideas, la cultura, las instituciones y los hechos concretos, que llevan a unos resultados en los que también intervienen el azar y las acciones individuales y colectivas. Como todo gran estudio, este también resuelve interrogantes y abre otros, no solo para el análisis de las nuevas formas de terrorismo sino también para los cambios globales en los que estamos sumergidos. Porque no todo está escrito...

por Carmen LÓPEZ ALONSO

Universidad Complutense

clopezal@cps.ucm.es

\section{Bibliografía}

Whewell, William (1988 [1858]). Theory of Scientific Method. Indianapolis: Hackett Publishing Company. (Citado en Sánchez-Cuenca, op. cit. p. 181).

Hacia una arquitectura del placer

Henri Lefebvre

(Madrid, Centro de Investigaciones Sociológicas, 2019)

La reciente publicación de este libro, cuyo reconocido autor no precisa de una presentación detallada, significa una gran novedad para los sociólogos y antropólogos urbanos. Sin embargo, en comparación con otras obras de Lefebvre, este libro supone «otra cosa», y esta "sensación» viene de forma rápida tras la lectura de sus primeras páginas 